\title{
SUPERAÇÃO IDEB: FORMAÇÃO CONTINUADA DE PROFESSORES DE EDUCAÇÃO BÁSICA
}

\author{
Sergio Vale da Paixão ${ }^{1}$ \\ https://orcid.org/0000-0002-7282-4645
}

\begin{abstract}
Resumo: A falta de diálogos e de conhecimentos sobre possibilidades de trabalho com projetos escolares, à luz das recentes teorias sobre metodologias inovadoras no ensino, favorecem práticas pedagógicas convencionais desprovidas de sentido para os estudantes na escola. Nesse sentido, propomos uma conversa neste texto, no intuito de socializar um projeto de extensão que realizamos há algum tempo junto a uma secretaria de educação municipal, no qual professores do ensino fundamental I estão mudando seu modo de planejar aulas e, principalmente, de trabalhar com projetos na escola. Tais mudanças são frutos de encontros de formação continuada, em que a pedagogia de projetos e as recentes teorias acerca da inovação na educação, uma vez que o assunto não foi contemplado a contento na formação inicial deste grupo de professores, segundo relato das próprias educadoras participantes são temas de trabalho. Com o projeto, temos alcançado resultados satisfatórios no exercício docente e nas avaliações com os alunos.
\end{abstract}

Palavras-chave: Pedagogia de projetos. Formação continuada. Extensão.

Abstract: The lack of dialogues and knowledge about possibilities of working with school
projects, linked of recent theories about innovative methodologies in teaching, collaborates
to conventional pedagogical practices that are meaningless for students in school. In this
sense, we propose a conversation in this text, in order to socialize an extension project that we
have been doing with a municipal education secretary, in which elementary school teachers
are changing their way of planning classes and, mainly, of working with projects at school.
These changes are the result of continuing education meetings through projects, in which
project pedagogy and recent theories about innovation in education, since the subject was
not satisfactorily contemplated in the initial formation of this group of teachers, according to

1 Pós doutor em Letras (UEM). Doutor em Psicologia pela UNESP. Mestre em Estudos da Linguagem (UEL). Professor do IFPR - campus Jacarezinho. Líder do grupo de pesquisa Ensino, Cultura, Linguagem e suas tecnologias (GECLIT - IFPR/CNPq) e participante do grupo de pesquisa Interação e Escrita (UEM). Coordenador da Especialização Educação e Sociedade no IFPR - Jacarezinho. Coordenador institucional do Programa de Residência Pedagógica - IFPR/Capes. E-mail: sergio. paixao@ifpr.edu.br 
reports of the own educators are the topics of working. Whit the project, we have seen good results in teacher's action an in evaluation with the students.

Keywords: Project pedagogy. Continuing education. Extension.

Resumen: La falta de diálogos y de conocimientos sobre posibilidades de trabajo con proyectos escolares, a la luz de las recientes teorías sobre metodologías innovadoras en la enseñanza, favorecen prácticas pedagógicas convencionales exentas de sentido para los estudiantes en la escuela. En este sentido, proponemos un diálogo en este texto, a fin de socializar un proyecto de extensión que realizamos hace algún tiempo junto a una secretaría de educación municipal, donde profesores de la educación primaria I están cambiando su modo de planificar clases y, sobre todo, de trabajar con proyectos en la escuela. Dichos cambios son frutos de encuentros de formación continuada, en que la pedagogía de proyectos y las recientes teorías acerca de la innovación en la educación, ya que el tema no fue contemplado a satisfacción en la formación inicial de este grupo de profesores, según relato de las propias educadoras participantes, son temas de trabajo. Con el proyecto, hemos logrado resultados satisfactorios en la actividad docente y en las evaluaciones con los alumnos.

Palabras clave: Pedagogía de proyectos. Formación continuada. Extensión.

Submetido em: 05/12/2018

Aceito em: 23/12/2018.

\section{INTRODUÇÃO}

Em tempos em que inovações tecnológicas têm sido incorporadas ao trabalho educativo e no qual a reflexão acerca da digitalização e virtualização do ensino e do uso de novas ferramentas didáticas, na era dos letramentos digitais, estão sendo utilizadas no contexto educacional, ainda é comum nos depararmos com discursos acerca da não participação dos alunos em atividades propostas pelos educadores nas instituições de ensino. Tais discursos criticam de modo acentuado a falta de envolvimento discente, mesmo quando são propostas "aulas diferentes" e são usadas certas tecnologias para "agradar" ou deixar a aula mais "legal" e "interessante", fazendo uso de expressões utilizadas frequentemente pelos professores. Questionamos com frequência em encontros de formação inicial e continuada de educadores, certos posicionamentos em relação a essa "não participação" dos alunos nas atividades. Apontamentos clássicos que há tempos estão presentes nos diálogos de sala de professores e em reuniões pedagógicas: "Como avalio a não participação e a aprendizagem dos alunos?" "O que é uma aula legal e interessante?" e quando o assunto é a leitura e produção de textos é bastante comum dizer que os alunos de hoje não 
leem mais e não escrevem com a qualidade de "outros tempos". E, em tempos de metodologias que utilizam recursos tecnológicos de ensino, questionamos: uma aula "legal", "divertida" em que estão presentes vídeos, sons, imagens e redes sociais resulta em aprendizagem, verdadeiramente? Ou ainda, quais são as motivações que estão presentes nessa construção de conhecimento?

Tais questionamentos são muito relevantes para refletirmos a formação do educador e analisarmos o verdadeiro papel da formação inicial e continuada e metodologias utilizadas nos momentos organizados para reuniões docentes durante o ano letivo. Interessa-nos refletir, assim como se faz nos discursos dos educadores a respeito da formação do aluno, o processo de construção do conhecimento "docente", daquele que, assim como os alunos, necessita de envolvimento, interação, diálogo e emoção para aprender. É nesse sentido que propomos uma comparação no que diz respeito à formação do aluno e do educador, no intuito de perceber e problematizar a formação de ambos, uma vez que o resultado esperado, independente do indivíduo em questão, é a aprendizagem.

\section{FORMAÇÃO CONTINUADA: REPENSANDO AS ESTRATÉGIAS DE TRABALHO}

É comum que se atribua o termo "formação continuada" ou "formação pedagógica” aos encontros de curta duração que ocorrem nas semanas pedagógicas, em datas específicas para esse fim. Palestras de poucas horas, recheadas de brincadeiras e humor, conhecidas como palestras motivacionais têm sido habitual em formações como essas.

Não desmerecemos a iniciativa, ao contrário, valorizamos esse tipo de trabalho por considerarmos que a emoção e a afetividade, muito presentes nessas atividades, são essenciais para um revigoramento das ações e reflexões acerca da prática pedagógica, porém questionamos práticas que não se preocupam verdadeiramente com a aprendizagem do educador. Um trabalho descontraído, dinâmico, didático é sempre muito bem-vindo, quando a proposta é, no mínimo, refletir sobre o processo de formação e, principalmente, encontrar soluções e oportunidades para uma evolução, um progresso naquilo que se configura uma fragilidade na prática docente. O interessante é o professor questionar seu próprio processo de formação: o que me move a aprender? Quais são as minhas dificuldades de aprendizagem? Como são, para mim, as 
aulas "legais", "interessantes" quando me coloco no papel de aprendiz? Será que aprendo com vídeos, com humor, com som, com a palestra motivacional? Tais práticas me levam a ser um educador melhor naquilo que talvez seja minha maior dificuldade em sala de aula? Quais são as minhas experiências como professor e em que elas podem colaborar para uma nova configuração de escola? Como estou lidando com o sujeito cognoscente, com o sujeito da experiência em minha prática pedagógica, visto como um ser envolvido em histórias, culturas e inserções sociais.

No dizer de Larrosa (2011, p.8),

O sujeito da experiência é como um território de passagem, como uma superfície de sensibilidade em que algo passa e que "isso que me passa", ao passar por mim ou em mim, deixa um vestígio, uma marca, um rastro, uma ferida. Daí que o sujeito da experiência não seja, em princípio, um sujeito ativo, um agente de sua própria experiência, mas um sujeito paciente, passional.

Ou, dito de outra maneira, a experiência não se faz, mas se padece. Colocar-se no lugar daquele que aprende, no lugar do aluno, possibilita ao educador compreender seu próprio processo de formação e coopera para uma reconfiguração dos modelos das semanas pedagógicas e reuniões escolares quando o assunto é a formação continuada.

Para atender as inúmeras demandas da escola contemporânea e em cumprimento à missão e aos valores do IFPR que é, dentre tantos outros, "promover a educação profissional e tecnológica, pública, de qualidade, socialmente referenciada, por meio do ensino, pesquisa e extensão, visando à formação de cidadãos críticos, autônomos e empreendedores, comprometidos com a sustentabilidade." (grifo do autor) surge a necessidade de se desenvolver o projeto de extensão "Superação IDEB: formação continuada de professores da educação básica" no município de Jacarezinho que se justifica pela real necessidade de fortalecer a formação continuada de professores.

Os resultados obtidos nos últimos anos nas avaliações externas aplicadas pelo MEC têm apresentado resultados não muito satisfatórios em algumas instituições de ensino de acordo com dados retirados do portal do INEP ${ }^{2}$. Tal resultado, a nosso ver, tem sido o reflexo da não atualização dos professores 2 Dados obtidos em: http://portal.inep.gov.br/educacao-basica/saeb/resultados.
Acesso em 19/03/2017 
no que diz respeito as novas metodologias de ensino que emergem a partir das pesquisas em Educação que consideram o atual contexto contemporâneo com suas tecnologias e afetos como necessários para o processo de ensino e aprendizagem. Sendo assim, lançamos mão do principal objetivo deste projeto que é o de colaborar para a formação continuada dos professores de escolas públicas municipais na cidade de Jacarezinho - PR. Junto dele, temos como objetivo específico proporcionar reflexões na formação inicial dos estudantes do curso de licenciatura em Química, único curso de licenciatura que temos no campus, para que possam compreender as novas posturas esperadas dos professores na atualidade.

\section{ASPECTOS METODOLÓGICOS}

Um dos grandes desafios da escola, não de hoje, mas durante toda sua existência é a compreensão de certos conceitos necessários para que o resultado do trabalho em qualquer nível de educação seja satisfatório. O que é escola? O que é educação? O que significa ensinar e aprender? Como o aluno aprende e, como eu ensino? E ainda, e talvez o mais importante: que conceito de aluno/ criança/adolescente eu tenho quando me preparo para "dar aula"?

Nossa inquietação não é algo inédito, afinal muitos outros já se preocuparam em questionar o papel da escola e da postura de muitos professores, alguns deles recém-formados e ingressantes das cadeiras docentes das escolas do Brasil, conforme nos aponta Tardif (2008). Muitos professores estão reproduzindo velhas práticas de ensino, ao invés de produzir novas formas e metodologias que se aproximem dos interesses, anseios e necessidades dessa geração digital, do fone de ouvido, da interação virtual e das informações rápidas.

Há de se reconhecer que muitas dessas práticas, hoje tidas como ultrapassadas, tiveram bom êxito há anos atrás e que por meio delas, muitas gerações se "formaram". Porém, é legítimo que se reconheça que estamos vivendo um novo momento em que qualquer que seja a fórmula, a regra ou a estratégia de se aprender algo, os alunos podem encontrar facilmente fora da escola, sem a presença do professor, em páginas de busca na rede mundial de computadores.

Algo que tem se tornado bastante evidente é que os alunos nunca aprenderam tanto, de formas diferentes e com motivações diferentes. Tomemos como referência o aprendizado de língua inglesa na escola. Basta fazer contato com os alunos e tê-los como "amigos" nas redes sociais para se perceber as 
expressões e escritas naquela língua, utilizadas em apresentações do Facebook, messengers, Twitter e outras. Constantemente, deparamo-nos com situações de alunos que questionam significados de palavras e expressões, que são rápida e facilmente esclarecidas pelos colegas, antes mesmo da tentativa de uma explicação pelo professor. Isso se dá pela grande quantidade de informações extraídas de jogos, páginas, blogs e letras de música disponíveis na internet e que são facilmente acessadas a qualquer instante. Assim questionamos "O que ensinamos na escola que não se aprende fora dela?". Diante desse questionamento particular, emerge uma hipótese: nunca estivemos tão próximos de fazer uma grande mudança no ensino quanto nos encontramos hoje.

Acreditamos e defendemos constantemente uma transformação na educação brasileira, não esperando do poder ou das políticas públicas tal iniciativa, mas na ideia de uma mudança institucional, uma verdadeira revolução dentro de cada escola. Uma vontade individual do professor, e de todos os envolvidos, de modificar internamente nas escolas as práticas pedagógicas fundamentadas naquilo que julgamos imprescindível para a construção de um ambiente educativo verdadeiramente significativo para os alunos, ou seja, o reconhecimento da identidade da escola, para que, a partir desse reconhecimento, um novo momento se instaure não somente dentro dos muros da instituição, mas na comunidade como um todo.

É válido considerar que uma motivação coletiva no tocante a uma transformação institucional, somente se dá a partir de ideias, muitas vezes solitárias e individuais, que precisam ser colocadas em prática, testadas, avaliadas e constantemente reorganizadas e melhoradas a cada prática.

A prática pode ser vista como um processo de aprendizagem através do qual os professores retraduzem sua formação e a adaptam à profissão, eliminando o que lhes parece inutilmente abstrato ou sem relação com a realidade vivida e conservando o que pode servir-lhes de uma maneira ou de outra (TARDIF, 2008, p. 53).

A iniciativa individual, os reflexos dela em pequenos grupos e a parceria com a administração da escola, no papel da direção e coordenação, podem, aos poucos, fazer mudanças significativas no espaço escolar construindo assim, uma nova escola, um novo lugar de ensinar e de se aprender com qualidade. Nossa crença nessa transformação é, portanto, fruto nossa particular experiência e na ousadia que sempre tivemos em transformar as aulas em momentos significativos e prazerosos, não apenas para os alunos, mas também 
para nós. Prazer esse não entendido apenas como bem-estar de uma aula divertida, diferente e "legal", mas em aprender, produzir e, principalmente, conhecer o mundo em que se vive repleto de linguagens, números, história, ciências, filosofia e de qualquer que seja o conteúdo da disciplina do currículo escolar. Vale dizer que “[...] não é pretensão questionar a importância de cada um desses conteúdos acadêmicos, mas tentar gerar uma reflexão sobre a forma e o contexto que são introduzidos aos alunos". (NOGUEIRA, 2008, p. 19)

Nossa preocupação é, sem dúvida, a de garantir a qualidade de educação, de modo que a aprendizagem possa acontecer de forma significativa, o que, naturalmente, proporciona motivação e qualidade de vida para o docente e impede que a indisciplina tenha espaço na sala de aula, dando lugar a produção, trabalho, construção de conhecimentos, etc. Assim, concordamos com as palavras de Paulo Freire quando afirma que se deve ter solidariedade social e política para se evitar um ensino elitista e autoritário como quem tem o exclusivo do "saber articulado" no papel do professor.

As escolas atendidas pelo projeto de extensão foram selecionadas junto aos gestores municipais da cidade de Jacarezinho - PR (Imagem I). Como já explicitado, foram contempladas as escolas e os professores que obtiveram notas baixas na avaliação IDEB em 2015/16 na fase inicial do projeto de extensão. No entanto, dada a excelente participação dos educadores e o bom desempenho nas atividades, o projeto de extensão passou a ser renovado desde então e atualmente já faz parte do calendário de formação continuada dos educadores do município de Jacarezinho - PR ao longo do ano.

\section{IMAGEM 1-REUNIÃO COM OS GESTORES MUNICIPAIS PARA PLANEJAMENTO}

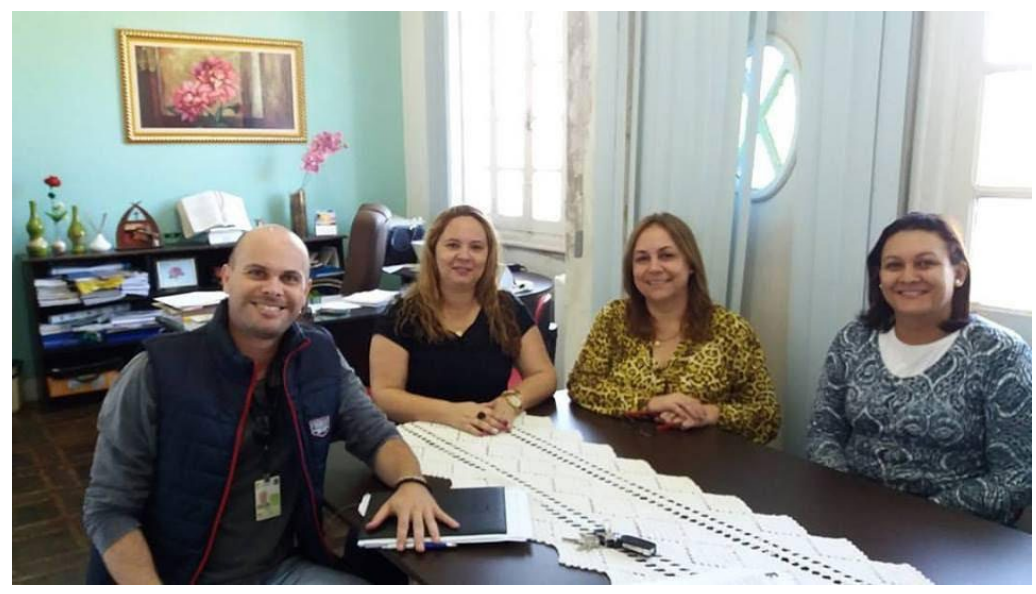

FONTE: AUTOR 
Utilizamos como procedimento metodológico para este projeto de extensão, encontros presenciais para a formação continuada dos professores. Os encontros acontecem bimestralmente ou conforme necessidade e disponibilidade de horários da escola. Além dos encontros coletivos bimestrais, que ocorrem com todos os professores e gestores das escolas atendidas, há também, reuniões individuais com os docentes a que chamamos de assessoria pedagógica.

Os encontros coletivos servem para que possamos, em formato de oficinais, estudar e elaborar estratégias de ensino que proporcionem um repensar e um agir docente colocando a ação e o fazer nas atividades de sala de aula sob responsabilidade dos alunos, reconhecendo o papel de mediação dos professores neste processo (HERNANDEZ; MONTSERRAT, 1998). As propostas estão fundamentadas nas pesquisas mais recentes sobre ensino e aprendizagem mediadas pelas tecnologias e na elaboração de projetos de ensino (NOGUEIRA, 2008) em que a cognição e a afetividade sejam indissociáveis (ARANTES, 2015).

De acordo com Moreno et al. (1999, p.46) "Os sentimentos podem constituir uma ponte de ligação privilegiada entre o conhecimento cotidiano, que se apoia numa série de procedimentos e técnicas de reflexão sobre algumas parcelas da realidade que nem sempre estão próximas dos interesses do alunado".

IMAGEM II - FORMAÇÃO CONTINUADA DOS PROFESSORES EM AÇÃO

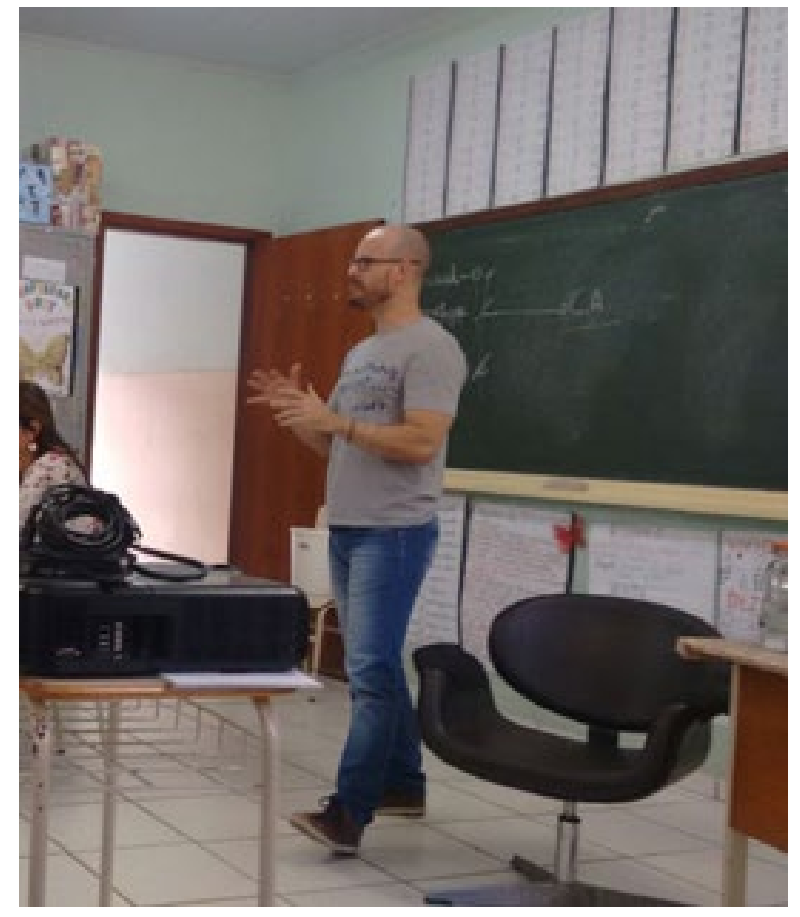

FONTE: AUTOR 
Como o projeto de extensão contou com a colaboração de um aluno bolsista no ano de 2016 e 2017, contamos também com sua colaboração ao longo das atividades no planejamento e desenvolvimento das atividades. Além do bolsista (Imagem IV), a participação dos alunos da graduação como voluntários do projeto (Imagem V) colabora significativamente no planejamento das atividades e durante as oficinas contribuindo para a organização e apoio às necessidades que emergem.

IMAGEM IV - BOLSISTA APRESENTANDO RESULTADOS PARCIAIS DO PROJETO DE EXTENSÃO EM EVENTO DO IFPR

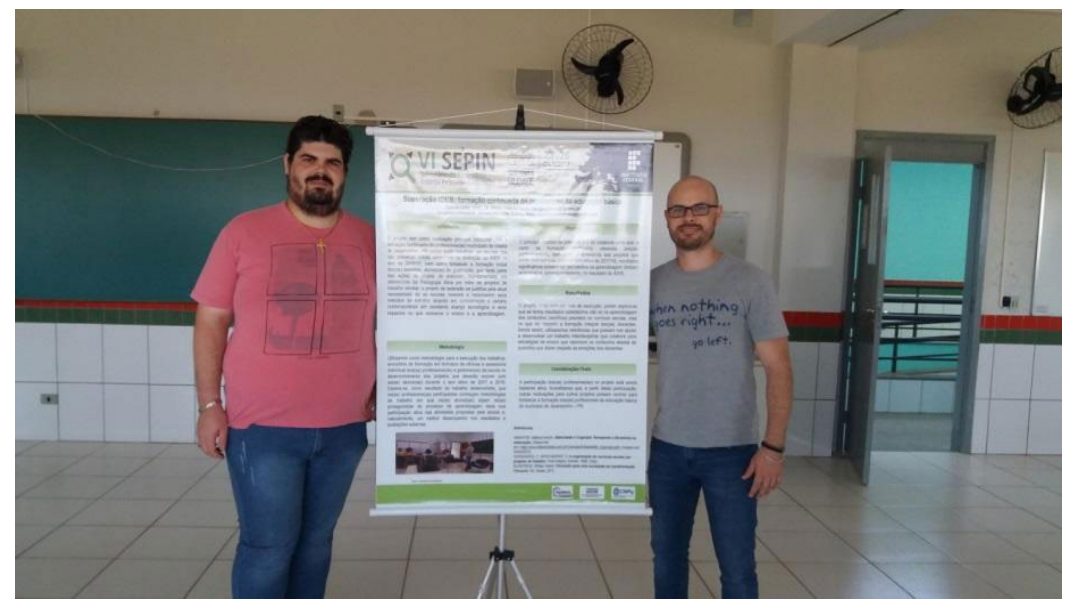

FONTE: AUTOR

IMAGEM V - ESTUDANTES VOLUNTÁRIOS DO CURSO DE LICENCIATURA EM QUÍMICA PARTICIPANDO DE AÇÕES DO PROJETO JUNTO AOS PROFESSORES.

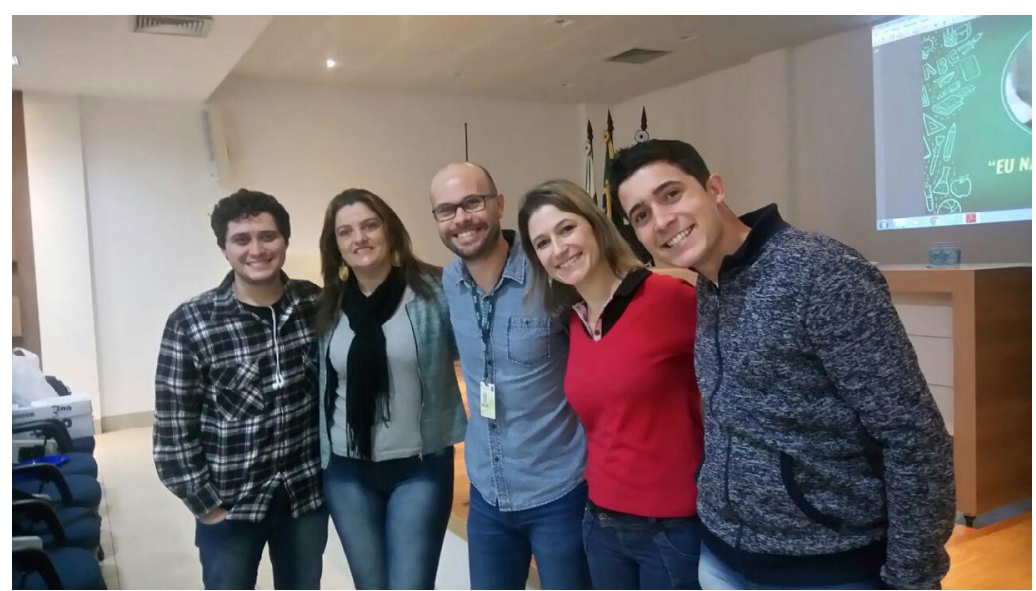

FONTE: AUTOR 
O projeto de extensão tem se mostrado eficaz e tem trazido excelentes resultados para o dia a dia da escola no que diz respeito à participação dos alunos nas atividades propostas pelos professores. Com reflexões constantes, os gestores e professores tem compreendido que a educação da atualidade exige cada vez mais novas práticas e novas metodologias que venham ao encontro na exigência do novo perfil de aluno que estão chegando aos bancos escolares nos últimos anos. Sendo assim, nosso esforço tem sido o de colaborar pra uma ressignificação dos processos na ação de ensinar e aprender, envolvendo não apenas os gestores e professores na ativa, mas também para os futuros professores, atuais acadêmicos do curso de Licenciatura em Química do campus do IFPR de Jacarezinho.

\section{A FORMAÇÃO DOS EDUCAdORES: PEDAGOGIA DE PROJE- TOS EM AÇÃO}

As orientações dadas aos professores participantes do projeto de extensão partem da premissa de que todo projeto se inicie a partir da observação atenta do professor mediador em se trabalhar determinados conteúdos com os estudantes. Conteúdos prescritos nos planejamentos ou mesmo necessários e emergentes a partir das curiosidades e necessidades de cada turma. A esses conteúdos, referenciamos na formação por Currículo. Um currículo em prol de uma uma educação libertadora e emancipatória, uma vez que compreendemos que

(...) tudo o que concerne aos sentimentos, aos afetos e às relações interpessoais, isto é, àqueles conhecimentos que continuamente usamos em nossas relações com os demais, parece não merecer nenhum tipo de educação, sendo dela excluídos e deixados nas mãos do acaso, que tende a reproduzir as condutas imperantes do meio. (MORENO et al.,1999, p.13)

É pensar a instituição escolar que atenda à demanda estabelecida e prevista pelos Parâmetros Curriculares Nacionais, que é a de organizar as disciplinas de base para o ensino brasileiro tendo como tema a afetividade.

Utilizando uma metáfora arquitetônica, pode-se dizer que, assim como se podem construir edifícios bem diferentes com os mesmos módulos, também se podem elaborar visões diversas sobre as pessoas, a ciência e a cultura com os mesmos conteúdos curriculares. (MORENO et al., 1999, p. 32). 
Assim, defendemos o trabalho com a formação integral dos estudantes no cotidiano da escola junto às disciplinas do currículo escolar e não em um momento ou em um projeto aleatório como um conteúdo isolado dos demais.

A função dessa escola é preparar para a inserção em uma sociedade desenvolvida; porém, os elementos necessários para essa inserção não estão todos contidos nas matérias tradicionais. Essas, inclusive, não devem constituir finalidades em si mesmas - seu objetivo não é formar especialista em Matemática, História, Educação Física, etc. -, mas proporcionar saberes necessários para o aluno poder utilizá-los em situações em que sejam solicitados (MORENO et al., 1999, p. 45).

Todos os conteúdos curriculares necessários para a construção de Projetos de Aprendizagem com os estudantes estão presentes em suas inúmeras posturas diante das coisas que os cercam, pelo olhar observador e atento do educador. As curiosidades dos alunos, o que consomem, o que lhes agradam, suas resistências, suas exigências, seus anseios e afetos, ou seja, os seus campos de experiências, de acordo com a Base Nacional Comum Curricular para a Educação Infantil. (BRASIL, 2018).

Precisamos "compreender, conhecer e reconhecer o jeito particular das crianças serem e estarem no mundo" (BRASIL, 1998, p. 22). Isso significa reconhecer o grande desafio da educação e de seus profissionais, e consideramos as inúmeras situações que fazem parte da vida social das crianças, em seus mais variados contextos, que é um universo curricular abastado para que se possam emergir projetos de melhor conhecer a vida, o outro, o entorno que as cercam.

As orientações dadas aos professores participantes do projeto de extensão são as de que o professor mediador, ao observar as necessidades de sua turma, ou seja, os conteúdos que devam ser trabalhados com os alunos, possa iniciar o primeiro passo para a construção do projeto da turma. Depois de realizada tal observação e compreendido qual o conteúdo dará início ao Projeto, inicia-se a escolha do Território, bem como a elaboração de Pergunta Exploratória que darão início às investigações e as descobertas do projeto das crianças.

A Pergunta Exploratória para essa faixa etária principalmente para os mais pequeninos, na maioria das vezes, é elaborada pelo educador para ser respondida por ele mesmo sobre a necessidade das crianças. É possível que pensemos: ao perceber, no dia a dia da sala de aula que as crianças não estão com estímulos suficientes para terem a autonomia necessária para realizarem determinadas atividades, tem-se o Índice Inicial, (ZABALLA, 2012, p. 40) a 
primeira impressão do que as crianças sabem, ou não sabem, sobre o assunto que será trabalhado no Projeto. A partir dessa observação, questiona-se: quais têm sido os estímulos recebidos para que as crianças desenvolvam autonomia para realizarem suas atividades? Esse pode ser um exemplo de Pergunta Exploratória construída pelo educador e, a partir da exploração do Território, ou seja, os espaços potenciais de pesquisa por meio de atividades de diálogos e investigação possa-se considerar o que será necessário realizar com as crianças ao longo do Projeto para que, a partir do Índice Formativo (ZABALLA, 2002 , p. 40), possam aprender mais e melhor sobre aquilo que inicialmente sabiam (ou não sabiam!) sobre o assunto.

Nas atividades com o Índice Formativo, “(...) pode-se oferecer às crianças condições para as aprendizagens que ocorrem nas brincadeiras e aquelas advindas de situações pedagógicas intencionais ou aprendizagens orientadas pelos adultos." (BRASIL, 1998, p. 23). Nota-se, então que a Pergunta Exploratória é elaborada pelo professor mediador sobre as necessidades de seus alunos, tendo-se como referência determinados conteúdos curriculares.

As atividades necessárias para alcançar os objetivos de aprendizagem para o desenvolvimento das crianças para que aprendam mais e melhor sobre os assuntos, a que chamamos de Índice Formativo, serão as mesmas que ocorrem naturalmente no dia a dia da escola, utilizando-se dos mais diferentes espaços e materiais comuns ao ambiente da instituição, porém, seguindo a temática que se estabeleceu no início do Projeto com a avaliação do Índice Inicial (ZABALLA, 2002, p. 40) pelo educador.

Os estímulos por meio das atividades lúdicas, as atividades com pintura e colagem, envolvendo as artes, comuns na escola do ensino fundamental, às canções, brincadeiras etc., enfim, as inúmeras estratégias que colaborarão para o desenvolvimento das crianças naquilo que inicialmente, quando da observação do Índice Inicial foi diagnosticado, são bem-vindas para colaborar com o aprendizado e desenvolvimento das habilidades dos aprendizes. Quando o projeto se encontra na etapa do Índice Formativo, faz-se necessário pensar em estratégias de aproximação das famílias e das pessoas para fazerem parte do Projeto. É exatamente nesse momento que se faz necessário pensar em estratégias de mobilização dos saberes dispostos na comunidade, assim como no currículo escolar, a fim de se buscar as respostas para as perguntas feitas pelas crianças no Índice Formativo. Com a participação da comunidade em rodas de conversa, em palestras formativas, em atividades coletivas é que 
cumprimos mais uma etapa da metodologia, ou seja, o envolvimento e a participação da Comunidade de Aprendizagem.

Por fim, chega o momento do Índice Final, etapa metodológica na qual todos os envolvidos no Projeto celebram as aprendizagens e reconhecem os saberes construídos do decorrer do trabalho além das formas como foram construídos e as parcerias necessárias para essa construção. Com certeza esse é um bom momento de socializar com todos os envolvidos no Projeto as inúmeras aprendizagens que o projeto proporcionou. Mais importante que o modo como se vai apresentar aos envolvidos, fica a certeza de que a culminância do projeto é a celebração da palavra mais importante ao final do trabalho e que deva ser destacada acima de qualquer outra situação, as aprendizagens. Portanto, a Pedagogia de Projetos tem sido um valioso instrumento de trabalho para o professor quando compreendida como uma metodologia que valoriza a experiência e curiosidade das crianças por meio das vivências de aprendizagem.

Procuramos, portanto, apresentar de forma resumida e pontual a metodologia utilizada na formação continuada dos educadores envolvidos no projeto de extensão Superação Ideb: formação continuada de professores que teve início no ano de 2016 e se mantém até hoje na cidade de Jacarezinho no interior do estado do Paraná, o que tem resultado em excelentes projetos nas escolas municipais e favorecido a formação integral das crianças envolvidas.

A partir dos projetos, temos percebido o quanto o investimento em formação é condição vital para o fortalecimento de práticas pedagógicas atuais em consonância com as demandas trazidas pelos alunos contemporâneos.

\section{CONSIDERAÇÕES FINAIS}

Em contextos cada dia mais marcados por avanços da tecnologia em que, com uma frequência cada vez maior, crianças e jovens encontram-se inseridos em espaços virtuais para comunicação e convivência social, torna-se urgente que a escola procure encontrar meios capazes de minimizar a distância entre o que se propõe por ela e a expectativa dessa instituição, por parte dos alunos.

O atual cenário nacional, com redução de gastos, minimiza as possibilidades de investimentos na educação, o que prejudica sobremaneira as possibilidades de formação continuada de professores nas escolas públicas impedindo assim reflexões sobre novos espaços escolares e novos métodos de trabalho 
que possam colaborar para uma convivência mais harmônica entre professores e aluno e que possam trazer resultados satisfatórios no ensino e na aprendizagem. Assim, a proposta que aqui procuramos relatar tendo como objetivo colaborar para a formação continuada dos professores de escolas públicas municipais, pretende dar atenção à formação dos docentes com vistas a minimizar os baixos rendimentos dos alunos das escolas atendidas possibilitando resultados satisfatórios não só na aprendizagem dos conteúdos científicos previstos no currículo escolar, mas no que diz respeito à formação integral dos discentes, uma vez que compreendemos que a cognição e a afetividade estão interligadas e são importantes para o processo de escolarização.

Sendo assim, ancoramos nossa pesquisa em referências que possam nos ajudar a desenvolver um trabalho que colabore para estratégias de ensino que valorizem os conteúdos aliados às questões que dizem respeito às emoções, favorecendo, portanto, a educação integral dos alunos.

Com as ações de formação e acompanhamentos às quais estamos desenvolvendo neste projeto, temos procurado dar visibilidade aos resultados do trabalho desenvolvido à comunidade acadêmica local, possibilitando transformações não apenas aos professores e alunos das escolas atendidas, mas a todos os docentes lotados na Secretaria Municipal de Educação de Jacarezinho - PR, bem como divulgar o trabalho e resultados nos eventos científicos regionais e em publicações científicas em periódicos especializados.

\section{REFERÊNCIAS}

ARANTES, Valéria Amorin. Afetividade e Cognição: Rompendo a Dicotomia na eeducação. Disponível em: http://www.teleminiweb.com.br/Ciencias/Artigos/afet_cognicao.pdf. Acesso em: 03 abr. 2015.

BRASIL. Parametros Curriculares Nacionais. (PCNs). Introdução. Ensino fundamental. Brasília: MEC/SEF, 1998.

BRASIL. Ministério da Educação. Base Nacional Comum Curricular. Proposta preliminar. Terceira versão de 20 de dezembro de 2017. Brasília: MEC, 2017. Disponível em: http://basenacionalcomum.mec.gov.br/. Acesso em: 2 dez. 2018.

HERNÁNDEZ, F.; MONTSERRAT, V. A organização do currículo escolar por projetos de trabalho. Porto Alegre: Artmed, 1998. 200p.

LARROSA, Jorge. Experiência e alteridade em educação. Revista Reflexão e Ação, Santa Cruz do Sul, v.19, n2, p.04-27, jul./dez. 2011. 
MORENO, Montserrat; SASTRE, Genoveva; LEAL, Aurora et al... Falemos de sentimentos: A afetividade como tema transversal. São Paulo: Moderna, 1999.

NOGUEIRA, Nilbo Ribeiro. Pedagogia de projetos: etapas, papéis e atores. São Paulo: Érica, 2008.

TARDIF, Maurice. Saberes docentes e formação profissional. 9. ed. Petrópolis: Vozes, 2008.

ZABALLA, Antoni. Enfoque Globalizador e Pensamento Complexo: uma proposta para o currículo escolar. Porto Alegre: Artmed Editora, 2002. 